\title{
ZVZCS PWM CONVERTER USING SECONDARY ACTIVE CLAMP
}

\author{
Marcel BODOR ${ }^{*}$, Jaroslav DUDRIK*, Ján PERDULAK ${ }^{* *}$ \\ *Department of Electrical Engineering and Mechatronics, Faculty of Electrical Engineering and Informatics, \\ Technical University of Košice, Letná 9, 04200 Košice, Slovak Republic, tel.: +421 55602 2276, e-mail: jaroslav.dudrik@tuke.sk \\ ${ }^{* *}$ Department of Theoretical and Experimental Electrical Engineering, Faculty of Electrical Engineering and Informatics, \\ Technical University of Košice, Letná 9, 04200 Košice, Slovak Republic, tel.: +421 55602 2592, e-mail: jan.perdulak@tuke.sk
}

\begin{abstract}
A novel zero-voltage and zero-current switching (ZVZCS) pulse-width modulation (PWM) converter is presented in this paper. An active energy recovery clamp in the secondary side provides conditions for zero-current switching (ZCS) of the transistors in the primary side of the DC/DC converter. Zero-voltage switching (ZVS) of the primary switches is achieved by the magnetizing current of the transformer. The active energy recovery clamp provides soft switching of the transistor located on the secondary side of the transformer. The principle of converter operation is explained and analyzed and experimental results obtained on the laboratory model are presented.
\end{abstract}

Keywords: DC/DC converter, zero voltage switching, zero current switching, soft switching, clamp circuit

\section{INTRODUCTION}

In recent days, there is an increasing demand for high performance load converters. This has resulted in an extra emphasis towards increasing the switching frequencies of the power devices in the circuit. While the reduction in the size and weight of the converters are the direct implications of this trend. However, the other side of the coin are issues like increased switching loss in the devices and electromagnetic compatibility problems.

MOSFETs are mainly used as switching devices in ZCZVS FB (full bridge) PWM converters. In spite of their several advantages, including very short switching times, they are not suitable for high power applications owing to an increased conduction loss with rise in voltage.

These days, IGBTs are replacing MOSFETs for high voltage, high power applications, since IGBTs have higher voltage rating, higher power density, and lower cost compared to MOSFETs [1]. On the other hand, the use of IGBTs is significantly reduced by their frequency switching, usually limited to $20-30 \mathrm{kHz}$ because of their tail current characteristic at turn-off [2]. To operate IGBTs at higher switching frequencies it is required to significantly reduce turn off switching losses.

Many topologies have been developed to solve this problem [1]-[15]. This topology uses an auxiliary circuit on the secondary side of the transformer to achieve ZCZVS and hence reduces the switching loss to zero. Generally, the ZVS of the leading-leg switches is achieved in a manner similar to that of ZVS FB PWM converters [3]-[4], [6] while ZCS of lagging-leg switches is achieved by resetting the primary current during the freewheeling period. The technical realization of the auxiliary circuit which provides reset of primary current is realized in different ways. The converter proposed in [3] has a simple auxiliary circuit which contains neither loss components nor active switches. Resetting of the primary current is achieved by using the energy of leakage inductance and clamp capacitor placed on the secondary side. The converter used in both [2] and [3] contains neither loss components nor active switches. Resetting of the primary current is achieved using transformer auxiliary winding inserted into the secondary side which makes this auxiliary circuit more complex. The converter [7] contains an active switch on the secondary side. This switch is used to control the clamping circuit. The clamp switch induces switching losses due to its hard switching, and the maximum output current is limited by the capacitance of the holding capacitor [3]. The blocking capacitor on the primary side of the transformer winding is used in the converter [5]. The auxiliary circuit contains an active switch and the transformer auxiliary winding which makes this circuit considerably complex and its parameter design is complicated [2].

The new energy recovery clamp presented in this paper clamps the collector-emitter voltage of the secondary switch at turn-off and recycles all the energy stored in the transformer leakage inductance. This energy is consequently transferred to the load. Furthermore, because the transformer leakage inductance energy is fully recovered, the efficiency of the converter is increased.

\section{OPERATION PRINCIPLE}

Fig. 1 shows the proposed converter with novel energy recovery clamp (patent pending) arranged for the use during the turn-off process of the secondary active switch. The proposed converter has nine operating modes within each operating half cycle. Operational analysis is shown in Fig. 2 and the corresponding operation waveforms are shown in Fig. 3. The detail description of the converter is presented in [6].

Mode $\mathbf{l}$ - interval $\left(\mathbf{t}_{\mathbf{0}}-\mathbf{t}_{\mathbf{l}}\right)$ : The transistors $\mathrm{T}_{1}, \mathrm{~T}_{2}$ are turned on with ZVS at $t_{0}$ because magnetizing current flows through diodes $D_{1}, D_{2}$ and rate of rise of the collector current is limited by the leakage inductance of the transformer. The collector current of the transistor $T_{S}$, which is turned on at $\mathrm{t}_{0}$ too, starts to flow and the capacitor $\mathrm{C}_{\mathrm{C}}$ is discharged. The rise of the capacitor discharging current is limited by the inductor $\mathrm{L}_{\mathrm{S}}$ in the clamp circuit.

Mode 2 - interval $\left(\mathbf{t}_{1}-\mathbf{t}_{2}\right)$ : The transformer leakage inductance reflected to the primary side causes the primary current $i_{P}$ to increase linearly while the secondary 


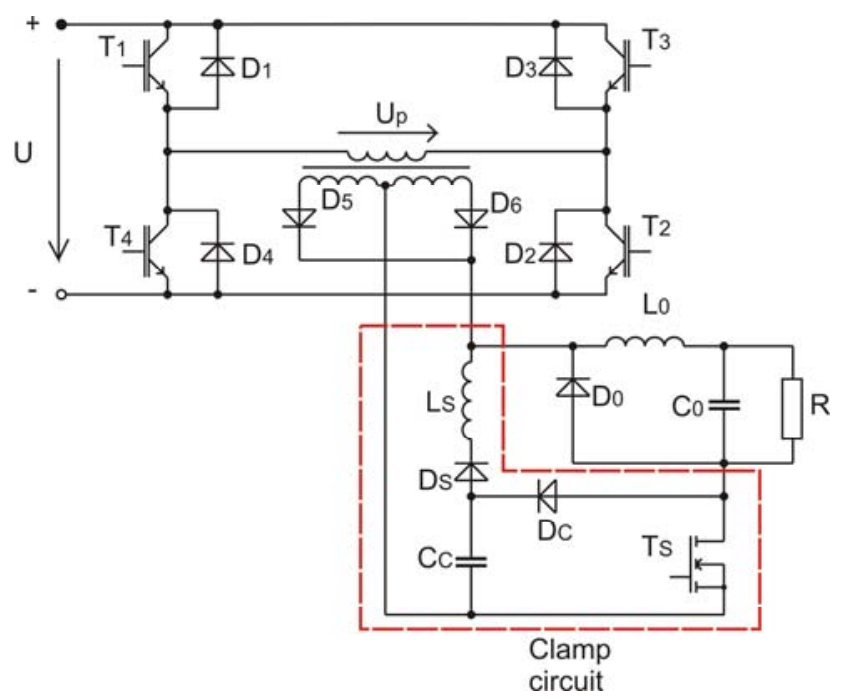

Fig. 1 Scheme of the proposed converter

voltage $u_{S}$ is zero as a result of commutation between output freewheeling diode $\mathrm{D}_{0}$ and rectifier diode $\mathrm{D}_{5}$.

Mode 3 - interval $\left(\mathbf{t}_{2}-\mathbf{t}_{3}\right)$ : The commutation between diode $\mathrm{D}_{5}$ and output freewheeling diode $\mathrm{D}_{0}$ is finished and the end of this interval the clamp capacitor current commutates to clamp diode $\mathrm{D}_{\mathrm{C}}$.

Mode 4 - interval $\left(\mathbf{t}_{3}-\mathbf{t}_{\mathbf{4}}\right)$ : The energy is delivered from the source to the load through transistors $T_{1}$ and $T_{2}$ which are conducting and from and the inductance $\mathrm{L}_{\mathrm{S}}$ as well. The smoothing inductance current is a sum of the secondary current and clamp inductance $\mathrm{L}_{\mathrm{S}}$ current.

Mode 5 - interval $\left(\mathbf{t}_{4}-\mathbf{t}_{\mathbf{5}}\right)$ : The energy is delivered from the source to the load.

Mode 6 - interval $\left(\mathbf{t}_{\mathbf{5}}-\mathbf{t}_{\mathbf{6}}\right)$ : At $\mathrm{t}_{5}$ the secondary transistor $\mathrm{T}_{\mathrm{S}}$ turns off. At this moment the commutation between transistor $T_{S}$ and clamp diode $D_{C}$ occurs and charging of the clamp capacitor $\mathrm{C}_{\mathrm{C}}$ starts. Afterwards, the commutation between $\mathrm{D}_{\mathrm{C}}, \mathrm{D}_{5}$ and output freewheeling diode $\mathrm{D}_{0}$ starts.

During the commutation, the energy stored in the leakage inductance is transferred to the clamp capacitor $\mathrm{C}_{\mathrm{C}}$ and consequently an overvoltage $\Delta \mathrm{U}_{\mathrm{S}}$ appears on secondary voltage. This clamped overvoltage can be calculated by the formula:

$$
\Delta U_{S}=I_{M A X} \sqrt{\frac{L_{L}}{C_{C}}}
$$

where: $\mathrm{I}_{\mathrm{MAX}}$ - current flowing through transistor $\mathrm{T}_{\mathrm{S}}$ at time $\mathrm{t}_{5}, \mathrm{~L}_{\mathrm{L}}-$ transformer leakage inductance, $\mathrm{C}_{\mathrm{C}}-$ clamp capacitor capacitance

Maximum clamped voltage on the clamp capacitor and transistor $\mathrm{T}_{\mathrm{S}}$ is:

$$
U_{C c M A X}=\Delta U_{S}+U \frac{N_{S}}{N_{P}}=I_{M A X} \sqrt{\frac{L_{L}}{C_{C}}}+U \frac{N_{S}}{N_{P}}
$$

where: $\mathrm{U}$ - converter supply voltage, $\mathrm{N}_{\mathrm{S}}$ - transformer secondary turns, $\mathrm{N}_{\mathrm{P}}$ - transformer primary turns

Mode 7 - interval $\left(\mathbf{t}_{\mathbf{6}}-\mathbf{t}_{\mathbf{7}}\right)$ : Only a small magnetizing current flows through the primary winding of transformer. The output current flows through the output freewheeling diode $\mathrm{D}_{0}$.

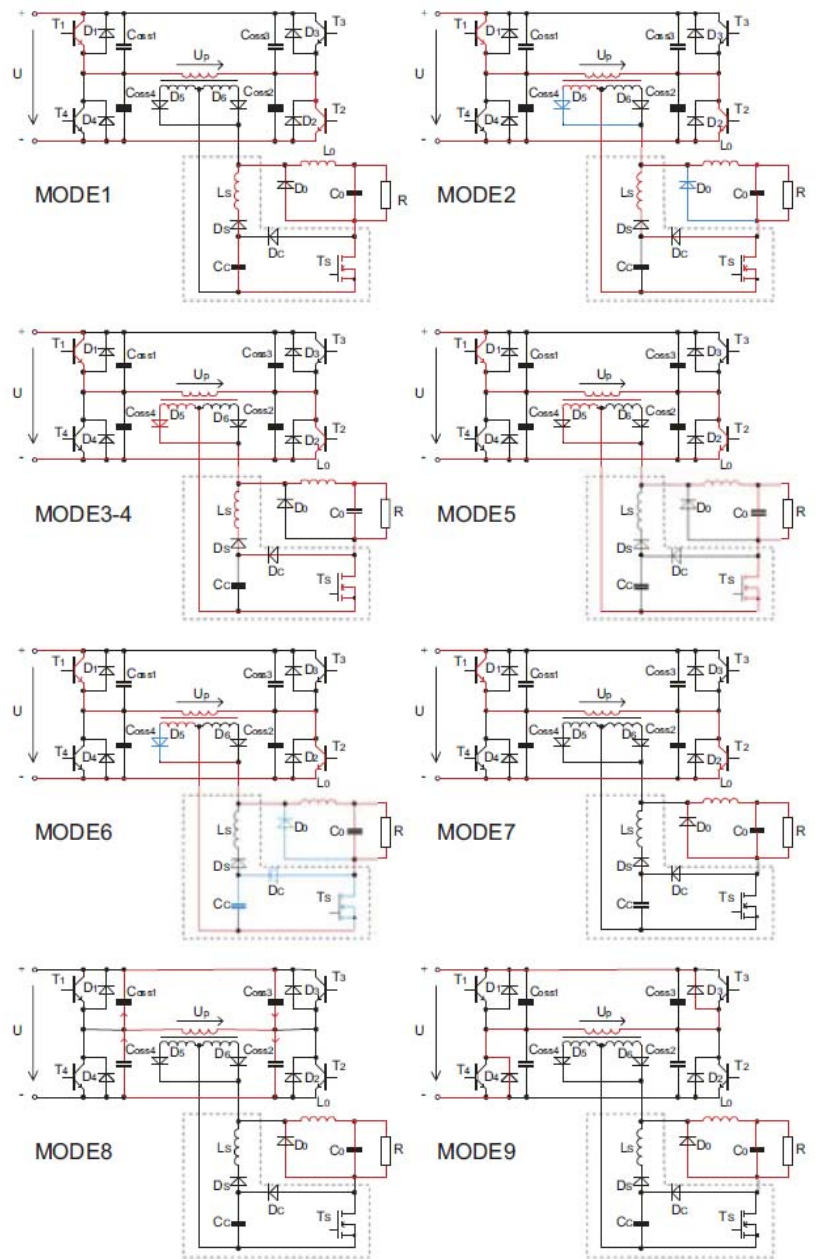

Fig. 2 Operation modes

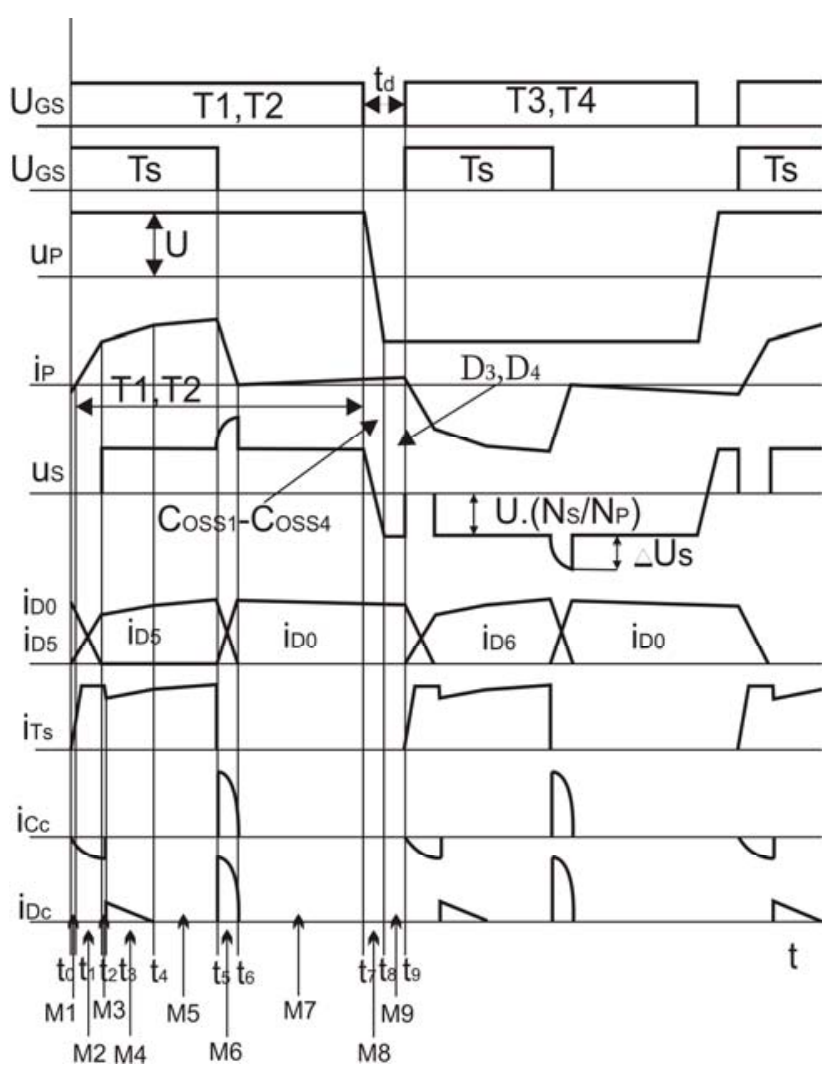

Fig. 3 Operation waveforms 
Mode 8 - interval $\left(\mathbf{t}_{\mathbf{7}}-\mathbf{t}_{\mathbf{8}}\right)$ : In interval, the transistors $T_{1}$ and $\mathrm{T}_{2}$ are turned off with ZCS. Only a small magnetizing current is switched off by transistors $T_{1}$ and $T_{2}$. The magnetizing current charges or discharges the internal output capacitances $\mathrm{C}_{\mathrm{OSS} 1}-\mathrm{C}_{\mathrm{OSS} 4}$ of the IBGT transistors $\mathrm{T}_{1}-\mathrm{T}_{4}$ respectively.

Mode 9 - interval $\left(\mathbf{t}_{\mathbf{8}}-\mathbf{t}_{\mathbf{9}}\right)$ : At $\mathrm{t}_{8}$, the antiparallel diodes $\mathrm{D}_{3}$ and $\mathrm{D}_{4}$ of the transistors $\mathrm{T}_{3}$ and $\mathrm{T}_{4}$ starts to lead the primary current and thus conditions for the ZVS for this transistors are ensured.

\section{EXPERIMENTAL RESULTS}

A prototype of the proposed ZVZCS PWM converter with active secondary energy recovery clamp has been built and tested to verify the principle of operation. The coaxial transformer used has been laboratory built with turn ratio $\mathrm{n}=6$. The magnetizing inductance of the transformer is $981,5 \mu \mathrm{H}$ and leakage inductance on the primary side is $18,5 \mu \mathrm{H}$. The prototype of the converter was supplied by $300 \mathrm{~V}_{\mathrm{DC}}$ and the switching frequency of IGBT's were $50 \mathrm{kHz}$. The main parameters are summarized in Table 1.

Table 1 Utilized components and parameters

\begin{tabular}{cc}
\hline $\mathrm{T}_{1}-\mathrm{T}_{4}$ & IRGP35B60PD \\
$\mathrm{T}_{\mathrm{S}}$ & IRFP4668 \\
$\mathrm{D}_{5}, \mathrm{D}_{6}$ & 80EBU02 \\
$\mathrm{D}_{\mathrm{S}}, \mathrm{D}_{\mathrm{C}}$ & 60EPU02 \\
$\mathrm{D}_{0}$ & $249 \mathrm{NQ} 135$ \\
$\mathrm{C}_{\mathrm{C}}$ & $220 \mathrm{nF}$ \\
$\mathrm{L}_{\mathrm{S}}$ & $7,4 \mu \mathrm{H}$ \\
$\mathrm{L}_{0}$ & $47 \mu \mathrm{H}$ \\
\hline
\end{tabular}

The voltage and current of the primary switch $\mathrm{T}_{4}$ and the transistor $\mathrm{T}_{\mathrm{S}}$ situated on the secondary side are shown in Fig. 4. Fig. 5 shows extended waveforms of the transistor $\mathrm{T}_{4}$. The value of the primary current decreases to the value of magnetizing current after turn off of the transistor $T_{S}$. This small magnetizing current is subsequently turned-off by the transistor $\mathrm{T}_{4}$ and as can be observed, turn off losses are negligible. The turn on of the transistor $\mathrm{T}_{4}$ is implemented under zero-voltage because its internal output capacitance is discharged before and only a small magnetizing current flows through its antiparallel diode $\mathrm{D}_{4}$ and thus the condition for ZVS is

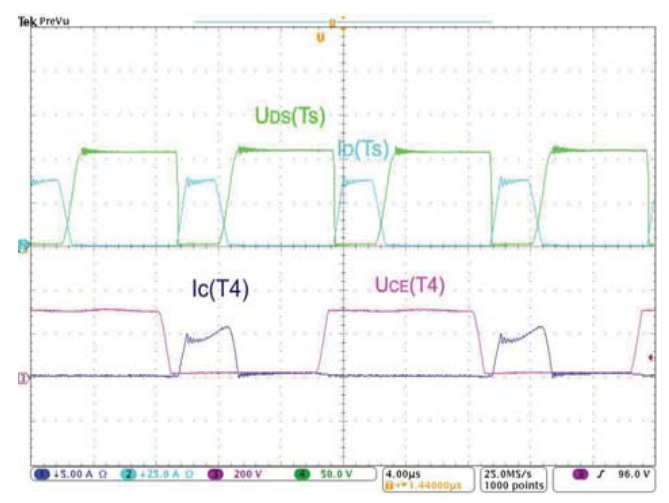

Fig. 4 Voltage and current of the secondary transistor $\mathrm{T}_{\mathrm{S}}$ and primary transistor $\mathrm{T}_{4}$ fulfilled. The rise of the collector current is limited by the leakage inductance of the transformer, therefore also ZCS is achieved.

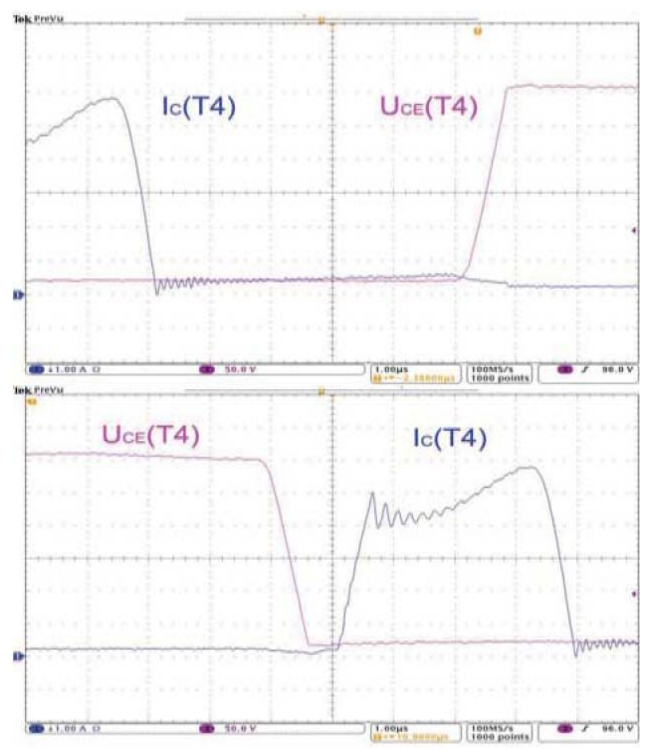

Fig. 5 Extended switch waveforms of the transistor $T_{4}$

The voltage and the collector current of the transistor $\mathrm{T}_{\mathrm{S}}$ are shown in Fig. 6. At the turn on of the transistor $\mathrm{T}_{\mathrm{S}}$ the collector-emitter voltage decreases to zero immediately. The rise of the collector current is significantly limited by the transformer's leakage inductance (reflected to the secondary side) and the clamp inductance $\mathrm{L}_{\mathrm{S}}$. So, the turn on losses are neglected.

From Fig. 7 it is evident that the voltage of the clamp capacitor rises at the same rate as the voltage of the transistor $\mathrm{T}_{\mathrm{S}}$. At the turn on moment of the transistor $\mathrm{T}_{\mathrm{S}}$ the energy stored in the clamp capacitor is delivered to the load through the diode $\mathrm{D}_{\mathrm{S}}$ and inductance $\mathrm{L}_{\mathrm{S}}$. The rate of the current rise is limited by the clamp inductance $\mathrm{L}_{\mathrm{S}}$.

For completeness, comparing waveforms of the clamp capacitor voltage with the voltage and the collector current of the transistor $\mathrm{T}_{\mathrm{S}}$ are provided in Fig. 8.

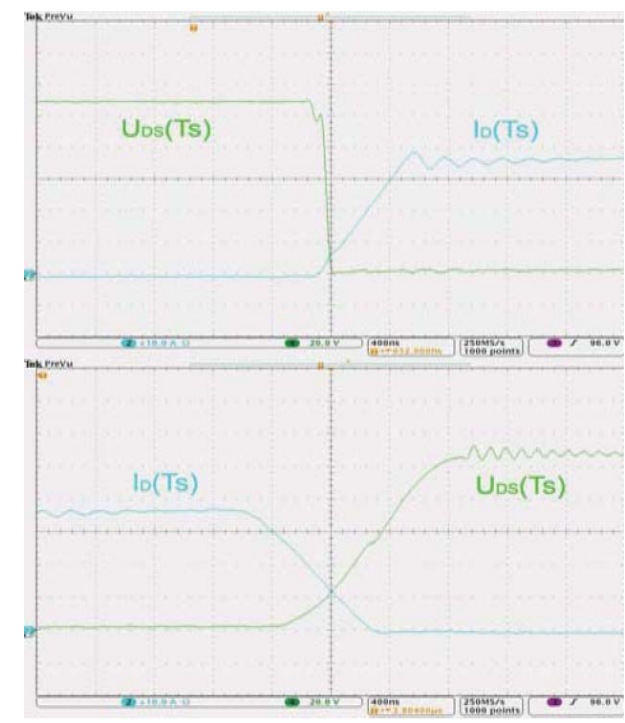

Fig. 6 Extended switch waveforms of the secondary transistor $\mathrm{T}_{\mathrm{S}}$ 


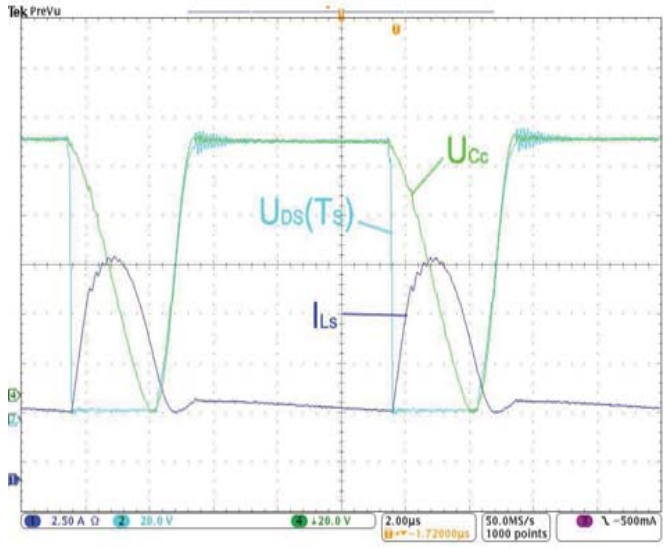

Fig. 7 Transistor $\mathrm{T}_{\mathrm{S}}$ voltage in comparison with clamp capacitor voltage and inductance $\mathrm{L}_{\mathrm{S}}$ current

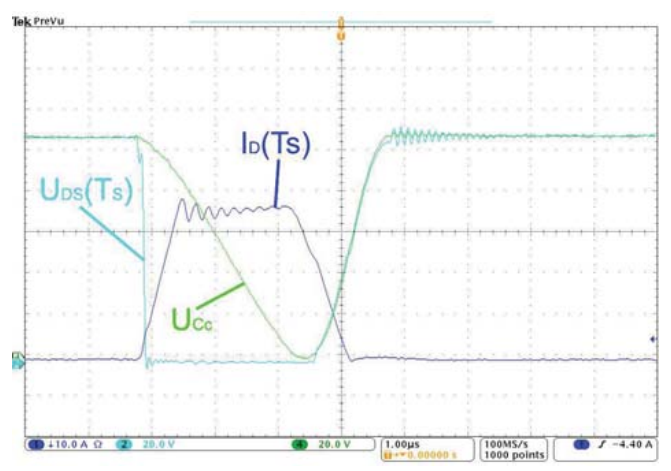

Fig. 8 Transistor $\mathrm{T}_{\mathrm{S}}$ switching waveforms in comparison with clamp capacitor voltage

\section{CONCLUSIONS}

The paper describes a ZVZCS PWM converter with a new active energy recovery clamp. The operating principle of the proposed converter is presented together with experimental results achieved on the laboratory model of the converter. This prototype of the converter was constructed by using IGBT's and it was successfully tested at $50 \mathrm{kHz}$ switching frequency. The experimental results obtained confirm the appropriateness of using the proposed topology of the converter with secondary energy recovery clamp and thus the zero-voltage turn-on and zero-current turn-off for all of the transistors $T_{1}-T_{4}$ in the inverter are achieved.

It is shown that experimental results are in very good accordance with the theoretical assumptions.

\section{ACKNOWLEDGMENT}

This work was supported by the Slovak Research and Development Agency under the contract No. APVV0185-10 and by Scientific Grant Agency of the Ministry of Education of Slovak Republic under the contract VEGA No. 1/0099/09. The authors also wish to thank for the support to the R\&D operational program Centre of excellence of power electronics systems and materials for their components. The project is funded by European Community, ERDF - European Regional Development Fund.

\section{REFERENCES}

[1] CHOI, H.-S. - KIM, J.-W. - CHO, B. H.: Novel zero-voltage and zero-current-switching (ZVZCS) full-bridge PWM converter using coupled output inductor, IEEE Transactions on Power Electronics, Sep. 2002, Vol. 17, No. 5, pp. 641-648.

[2] CHO, J. G. - BAEK, J. W. - YOO, D. W. - LEE, H. S. - RIM, G. H.: Novel zero-voltage and zerocurrent-switching (ZVZCS) full bridge PWM converter using transformer auxiliary winding, Power Electronics Specialists Conference, 1997. PESC '97 Record., 28th Annual IEEE, June 22-27, 1997, Vol. 1, pp. 227-232.

[3] CHEN, T.-F. - CHENG, S.: A Novel Zero-Voltage Zero-Current Switching Full-Bridge PWM Converter Using Improved Secondary Active Clamp, 2006 IEEE International Symposium on Industrial Electronics, July 9-13, 2006, Vol. 3, pp. 1683-1687.

[4] CHO, J.-G. - BAEK, J.-W. - JEONG, Ch.-Y. RIM, G.-H.: Novel zero-voltage and zero-currentswitching full-bridge PWM converter using a simple auxiliary circuit, IEEE Transactions on Industry Applications, Jan./Feb. 1999, Vol. 35, No. 1, pp. 1520.

[5] JANGWANITLERT, A. - OLEJNICZAK, K. J. BALDA, J. C.: "An improved zero-voltage and zerocurrent-switching PWM full-bridge DC-DC converter," Industrial Electronics Society, 2003. IECON '03. The 29th Annual Conference of the IEEE, Nov. 2-6, 2003, Vol. 2, pp. 1685-1690.

[6] DUDRIK, J. - RUŠČIN, V.: Voltage fed zerovoltage zero-current switching PWM DC-DC converter, 13th International Power Electronics and Motion Control Conference, 2008, (EPE-PEMC 2008), Sep. 1-3, 2008, pp. 295-300.

[7] CHO J.-G. - JEONG, Ch.-Y. - LEE, F. C. Y.: "Zerovoltage and zero-current-switching full-bridge PWM converter using secondary active clamp," IEEE Transactions on Power Electronics, July 1998, Vol. 13, No. 4, pp. 601-607.

[8] DUDRIK, J. - OETTER, J.: Soft-Switching PWM DC-DC Converter for High Power Applications, 12th International Power Electronics and Motion Control Conference, 2006, (EPE-PEMC 2006), Aug. 30, 2006-Sept. 1, 2006, pp.739-744.

[9] PETROV, S.: Prospective Topologies of the Welding Inverters. Sovremennaja Elektronika, 2009, No. 1, pp. 36-45. (in Russian)

[10] TRIP, N. D.: A new active snubber for dc-dc boost converters, 8th International Conference on Engineering of Modern Electric System, Proceedings, (EMES'05), Section Electronical Engineering, Oradea, Romania, May 2005, pp. 124127.

[11] HAMAR, J. - NAGY, I. - STUMP, P. - OHSAKI, H. - MASADA, E.: New Dual Channel Quasi Resonant DC-DC Converter Topologies for 
Distributed Energy Utilization, 13th International Power Electronics and Motion Control Conference (EPE-PEMC 2008), Sep. 1-3, 2008, Poznan, Poland, 2008, pp. 1778-1785, ISBN 978-1-4244-1742-1.

[12] CHLEBIŠ, P.: Soft Switching Converters, VŠB Ostrava, 2004, p. 148, ISBN 80-248-0643-6. (in Czech)

[13] LEUCHTER, J. - BAUER, P. - ZOBAA, A. F.: Power Electronics and Energy Management of Hybrid Power Sources with Supercapacitors, Proceedings of the 5th IET International Conference on Power Electronics, Machines and Drives (PEMD 2010), Brighton UK, 2010, pp. 1-6, ISBN 978-184919-231-6.

[14] STUMPF, P. - BARTAL, P. - VARGA, Z. - SEPSI, T. D. - JARDAN, R. K. - NAGY, I.: Comparison of Two Approaches in PWM Technique, 15th International Conference on Electrical Drives and Power Electronics (EDPE 2009): 4th Joint CroatiaSlovakia Conference, Oct. 12-14, 2009, Dubrovnik, Croatia, Zagreb: KoREMA, 2009. pp. 1-10, ISBN 978-953-6037-56-8.

[15] ŠPÁNIK, P. - DOBRUCKÝ, B. - FRÍVALDSKÝ, M. - DRGOŇA, P. - KURYTNIK, I.: Measurement of Switching Losses in Power Transistor Structure. Magazine of Electronics \& Electrical Engineering, Litva, Kaunas, 2008, No. 2, pp. 75-78, ISSN 13921215.

Received June 22, 2011, accepted September 16, 2011

\section{BIOGRAPHIES}

Marcel Bodor was born on 14.11.1984 in Lučenec (Slovakia). He received the M.Sc. degree in electrical engineering from the Technical University of Košice, Slovakia, in 2009. He is currently Ph.D. student at the Department of Electrical Engineering and Mechatronics, Technical University of Košice, where he is engaged in research. His primary interest is power electronics.

Jaroslav Dudrik received the M.S. and Ph.D. degrees in electrical engineering from the Technical University of Košice, Slovakia, in 1976 and 1987, respectively. He is currently full professor of Electrical Engineering at the Department of Electrical Engineering and Mechatronics, Technical University of Košice, where he is engaged in teaching and research. His primary interest is power electronics. His field of research includes dc-to-dc converters, high power soft switching converters, converters for renewable energy sources and control theory of converters.

Ján Perdul'ak received the M.Sc. degrees in electrical engineering from the Technical University of Košice, Slovakia, in 2010. He is currently Ph.D. student of Theoretical Engineering at the Department of Theoretical Electrical Engineering and Electrical Measurement, Technical University of Košice, where he is engaged in research. His primary interest is power electronics. His field of research includes dc-to-dc converters, converters for renewable energy sources and control theory of converters. 